\title{
Online monitoring of Cold Metal Transfer (CMT) process using Infrared Thermography
}

\author{
by Renil Thomas $\mathrm{K}^{\star}$, Nithin P.V*,Krishnan Balasubramaniam*, Prabhu Rajagopal*, K.V. Phani \\ Prabhakar $^{\star \star}$, G. Padmanabham ${ }^{\star \star}$, Frank Riedel ${ }^{\star \star \star}$ and Markus Puschmann ${ }^{\star \star \star}$ \\ * Center for Non-Destructive Evaluation, Indian Institute of Technology Madras, India, ktrenil@gmail.com \\ **International Advanced Research Centre for Powder Metallurgy and New Materials, Hyderabad, India \\ ***Fraunhofer Institute for Machine Tools and Forming Technology IWU, Chemnitz,Germay
}

\begin{abstract}
Online (passive) thermographic inspection of overlap joints of aluminium and zinc coated steel sheets made by CMT weld brazing process is explored. Different experimental trails were conducted for demonstrating the feasibility of thermographic inspection to detect the porosities, improper weld bead and to differentiate the pre weld temperature. The whole process is monitored using infrared cameras in different wavelength region. Image analysis algorithms were developed to reconstruct the thermal images that contain the signatures of the weld defects and to extract the pre weld temperature and its evolution with distance from the centre of the weld torch. Post-weld radiography lends strong support to the observations.
\end{abstract}

\section{Introduction}

Light weight construction strategy is inevitable in the automobile industry to meet the increasing demand of fuel efficiency, low cost of production and environmental impact considerations. Combination of different materials with different physical, mechanical and metallurgical properties is the future scope for lightweight structures. The research is progressing towards the achievement of lightweight structures made of aluminium alloys, advance fiber reinforce polymers, aluminium-steel combinations etc. The main focus in this respect is on the joining of steel and aluminium sheets as it combines the low specific weight, excellent usability of aluminium and strength, low cost features of steel. There are different feasible joining technologies for sheet metals such as pressing, joining by forming, bonding by chemical hardening adhesives, joining by welding, joining by soldering etc. Cold Metal Transfer process is a recent development in welding technology which is suitable for the joining of aluminium and steel thin sheets.

CMT is a modified Metal Inert Gas welding process which was invented by Fronius company. From the current and voltage waveforms of the CMT process we can divide the cycle in to three phases[1]- The peak current phase, the background current phase and the short circuiting phase. In the last phase when the wire comes in contact with the weld pool, conventional MIG process responds to it by a rapid rise in current which results in the fracture of liquid bridge that causes high heat input. But in CMT process, during this phase current is reduced to a low level thus achieving a low heat input which helps us in controlling the total heat input in the process. Simultaneously the wire is pulled back which assists the fracture of liquid bridge and transfer into the weld pool. Due to this combined effect of electrical and mechanical processes low heat input and spatter free welds are achieved.

There is a great interest in quantitatively defining the weld joint quality and thus optimizing the weld characteristics. Conventional post weld NDT methods are very well established, but consumes time, cost and labour. Welding is naturally a high temperature process with a moving heat source with presence of high thermal radiations in the weld vicinity. This restricts the employment of conventional contact NDT methods such as ultrasonics, eddy current etc., for real time monitoring. Even a non-contact method such as IR Thermography is adversely influenced by the high thermal radiations from the weld region. In this study, the feasibility of using non-contact infrared thermography as a potential tool to monitor the CMT welding process is explored. The presence of internal defects such as porosity, lack of filler material deposition and formation of improper weld bead produce perturbations in the surface temperature which can be identified using an Infrared thermography technique. In the last few decades several efforts have been reported on the online monitoring of different welding processes and its ability for detecting defects generated during the welding process. Infrared thermography for monitoring arc position, geometry faults[2], depth of penetration[3] etc in arc welding process has been reported earlier. In another study[4] it has been reported that the variation of welding speed, presence of surface pollution, misalignment between the similar and dissimilar plates, etc can be identified from the evolution of surface temperature using infrared pyrometers for continuous laser welding process. Works have been reported on the offset positioned thermal imaging strategies and defect extraction using different image processing algorithms [5] for the real time monitoring of welds. 
In this paper the results of two series of experiments conducted for detecting the internal defects, geometric perturbations and the pre weld temperature are discussed.

\section{Experimental procedure}

Table 1. Infrared camera details used for the experiments

\begin{tabular}{|c|c|c|c|c|}
\hline $\begin{array}{c}\text { Experiment } \\
\text { Names }\end{array}$ & Camera & $\begin{array}{c}\text { Wavelength Range } \\
(\mu \mathrm{m})\end{array}$ & $\begin{array}{c}\text { Temperature Range } \\
\left({ }^{\circ} \mathrm{C}\right)\end{array}$ & $\begin{array}{c}\text { Frame Rate } \\
(\mathrm{Hz})\end{array}$ \\
\hline Series 1 & Long Wave IR & $8-11$ & $150-1200$ & 50 \\
\hline Series 2 & Medium Wave IR & $3-5$ & $135-300$ & 150 \\
\hline
\end{tabular}

The different experimental studies conducted to monitor the CMT welding process is presented in table 1 . All experiments were conducted using $300 \times 100 \times 2 \mathrm{~mm}$ galvanized steel plates and $300 \times 100 \times 1.2 \mathrm{~mm}$ aluminium plates. The plates were lap welded with an overlapping distance of $13 \mathrm{~mm}$ produced by fixing the plates on the work bench using various fixtures.

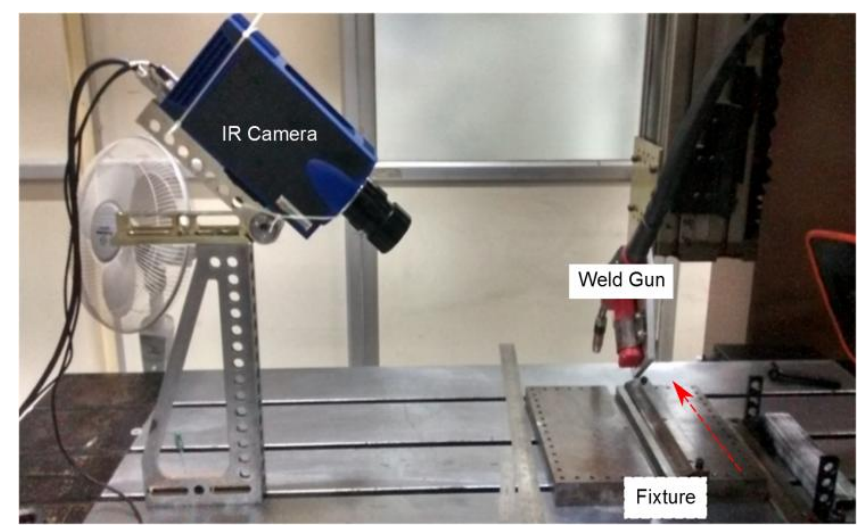

Fig. 1. Experiment setup for Series 1

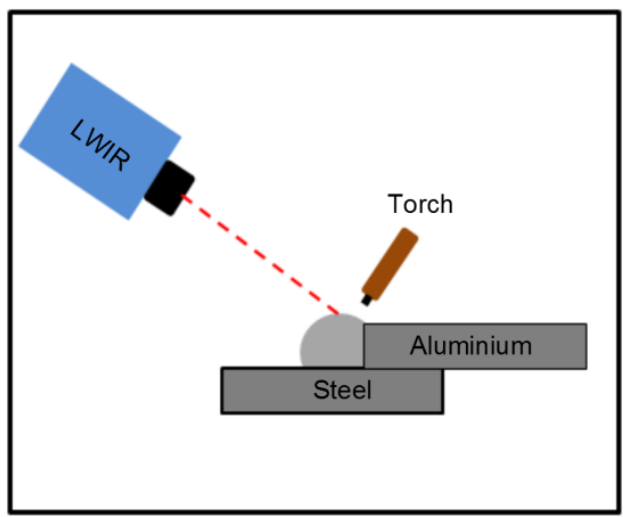

Fig. 2. Schematic of the Experiment Series 1

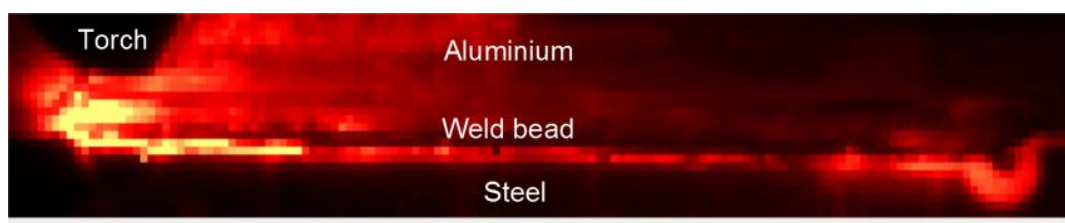

Fig. 3. Thermal image obtained in experiment series 1

The objective of the first series of experiments was to demonstrate the feasibility of using infrared thermography to detect the porosities, improper weld bead developed during the welding process. The experiment setup for the first series of experiments is shown in figure 1. The welding direction is shown as red arrow mark in figure 1 . The schematic diagram for the experiment series 1 and the thermal image obtained are shown in figure 2 and figure 3 respectively. The welding parameters used for the experiment series 1 is given in table 2 .

Table 2. Weld parameters for experiment series 1

\begin{tabular}{|c|c|c|c|c|}
\hline $\begin{array}{c}\text { Weld } \\
\text { Name }\end{array}$ & $\begin{array}{c}\text { Welding Speed } \\
(\mathrm{m} / \mathrm{min})\end{array}$ & $\begin{array}{c}\text { Wire Feed Rate } \\
(\mathrm{m} / \mathrm{min})\end{array}$ & $\begin{array}{c}\text { Voltage } \\
(\mathrm{V})\end{array}$ & $\begin{array}{c}\text { Current } \\
(\mathrm{A})\end{array}$ \\
\hline S1A & 1 & 4.5 & 10.5 & 70 \\
\hline S1B & 1.5 & 5 & 11 & 91 \\
\hline S1C & 0.5 & 5 & 11.3 & 91 \\
\hline
\end{tabular}

The objective of the second series of experiments is to acquire the pre weld surface temperature which is a significant factor for the proper weld formation in aluminium-steel joints. The acquisition of pre weld surface temperature was achieved by keeping the weld torch stationary and moving the work bench. The infrared camera was positioned in a different platform just above the torch in such a way that the immediate region before the occurrence of the weld can be imaged. Experiment series 2 setup is show in figure 4. The thermal image obtained and the schematic of the experiment setup are shown in figure 5 and figure 6 respectively. The weld parameters used for experiment series 2 is given in table 3. 
Table 3. Weld parameters for experiment series 2

\begin{tabular}{|c|c|c|c|c|}
\hline $\begin{array}{c}\text { Weld } \\
\text { Name }\end{array}$ & $\begin{array}{c}\text { Welding Speed } \\
(\mathrm{m} / \mathrm{min})\end{array}$ & $\begin{array}{c}\text { Wire Feed Rate } \\
(\mathrm{m} / \mathrm{min})\end{array}$ & $\begin{array}{c}\text { Voltage } \\
(\mathrm{V})\end{array}$ & $\begin{array}{c}\text { Current } \\
(\mathrm{A})\end{array}$ \\
\hline S2A & 1 & 4.5 & 10.5 & 80 \\
\hline S2B & 0.5 & 4.5 & 10.7 & 82 \\
\hline
\end{tabular}

The plates are cut into required dimensions and cleaned the surface with ethanol to remove any oil or grease and fixed to the work bench using fixtures. The data was acquired using the thermal imaging camera throughout the welding process.

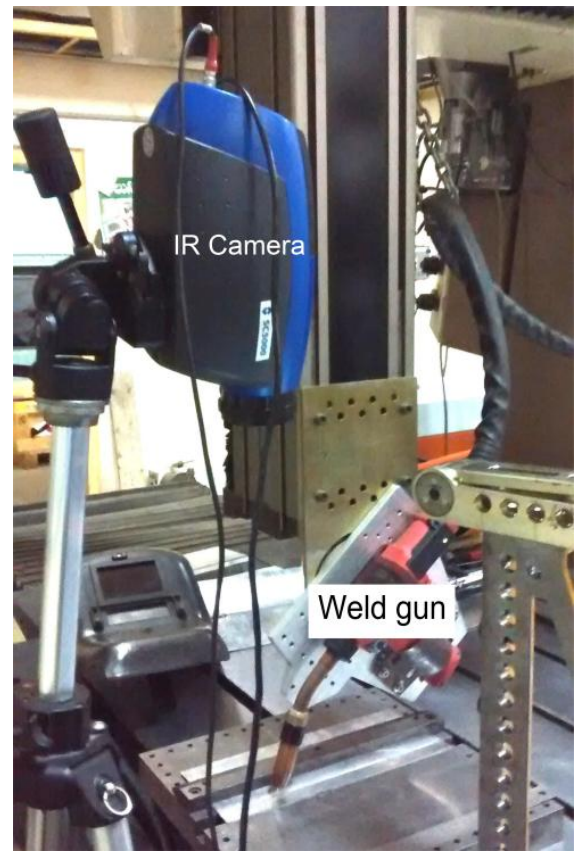

Fig. 4. Experiment Series 2 setup

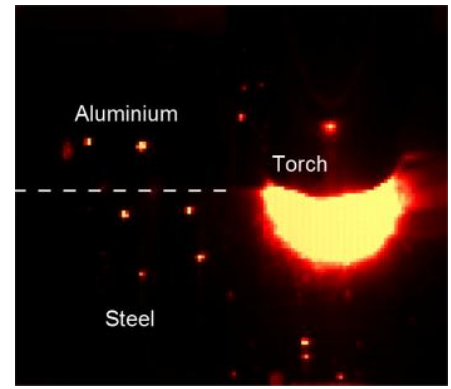

Fig. 5. Thermal image obtained in experiment series 2

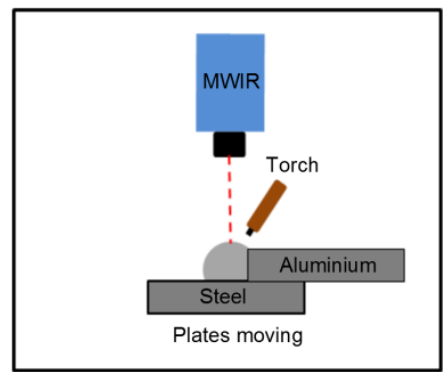

Fig. 6. Schematic of experiment series 2

\section{Thermal images: analysis and results}

Different algorithms were developed in $\mathrm{MATLAB}^{\circledR}$ for image reconstruction using the surface temperature information collected. Radiographic data were taken on the weld samples to compare the results obtained by image reconstructions.

\subsection{Experiment series 1}
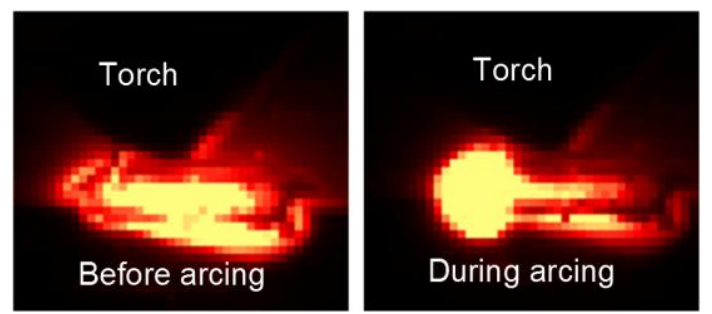

Fig. 7. Thermal image before and during arcing process 


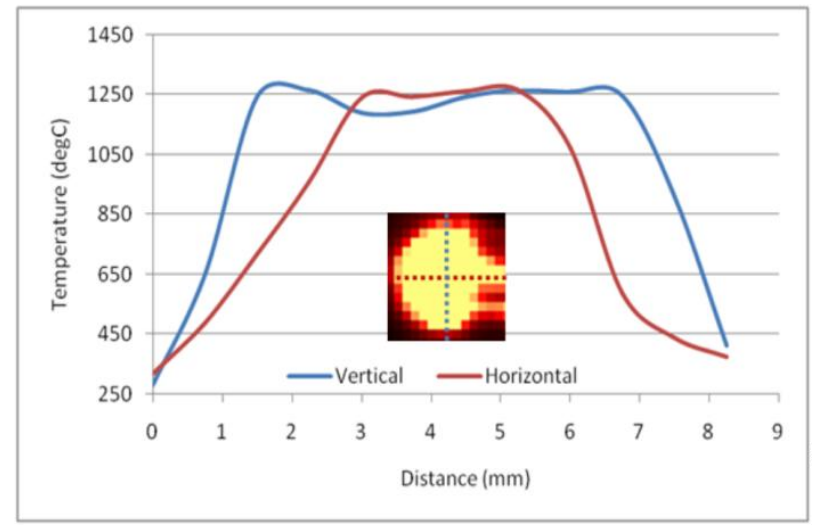

Fig. 8. Temperature distribution in an arc

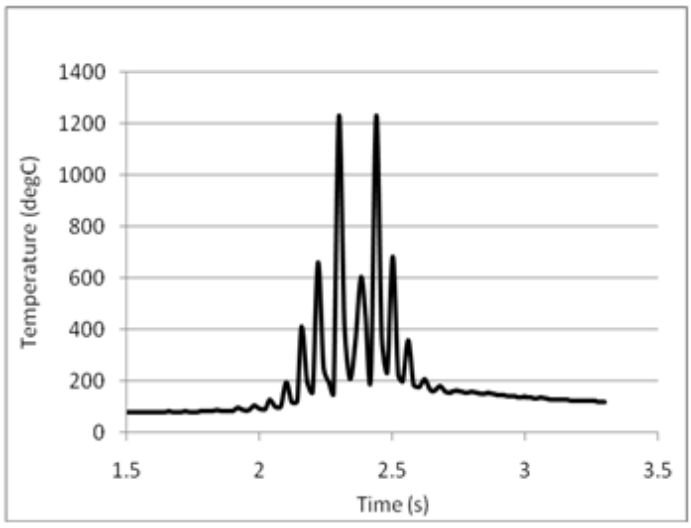

Fig. 9. Temperature Vs. Time graph for a pixel

The time temperature graph of a particular pixel in the weld bead is shown in figure 9. The graph consists of numerous peaks due to the wire progression and regression operations in the CMT process. The droplet transfer process during the CMT welding process were not able to pick up by the IR Camera due to the presence of arc. Figure 7 shows the thermal images captured during the arcing process and Figure 8 shows the vertical and horizontal distribution of temperatures in the captured thermal image of the arc. The extraction of required information from each pixel by excluding the above said effect is achieved through an image processing algorithm which offsets the temperature vs. time information. A new thermal image video is reconstructed by this which contains the cooling information of all pixels.

The photographs of the welded samples are shown in figure 10. Radiographic tests have been carried out on the weld samples to detect the defects inside the weld bead.

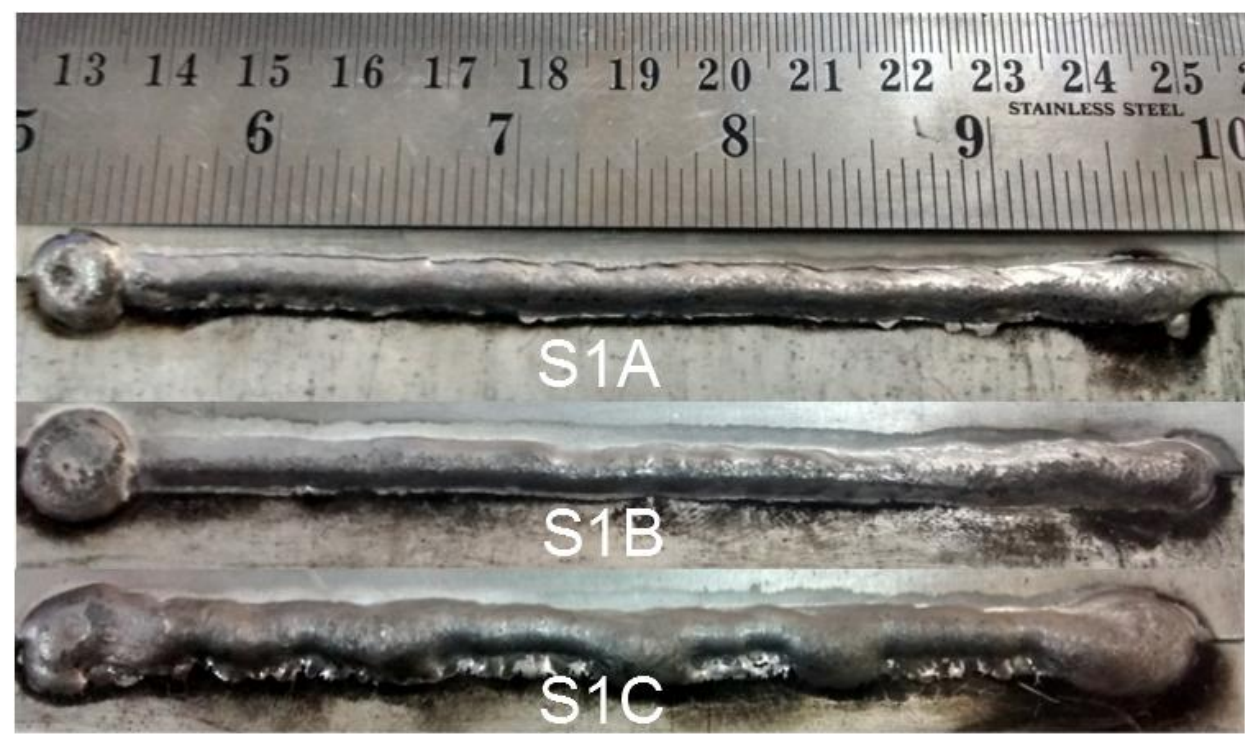

Fig. 10. Real images of the weld

Figure 11 shows the comparison between the radiography images and the frames of the reconstructed image sequences. The reconstructed images show in figure 11 are the temperatures reached by each pixel after 1 second of passing of the torch from their locations. The reconstructed images are in good agreement with the radiographic images. In weld S1B, a cluster of porosities can be seen on the right side of the respective radiographic image. At the same locations a difference in the surface temperature can be seen in the reconstructed image. The plausible reason for observing these hot spots could be due to the hindrance offered by the cluster of porosities towards the heat flow. And in weld S1C the improper geometry of the weld bead is clearly picked up using the algorithm. 

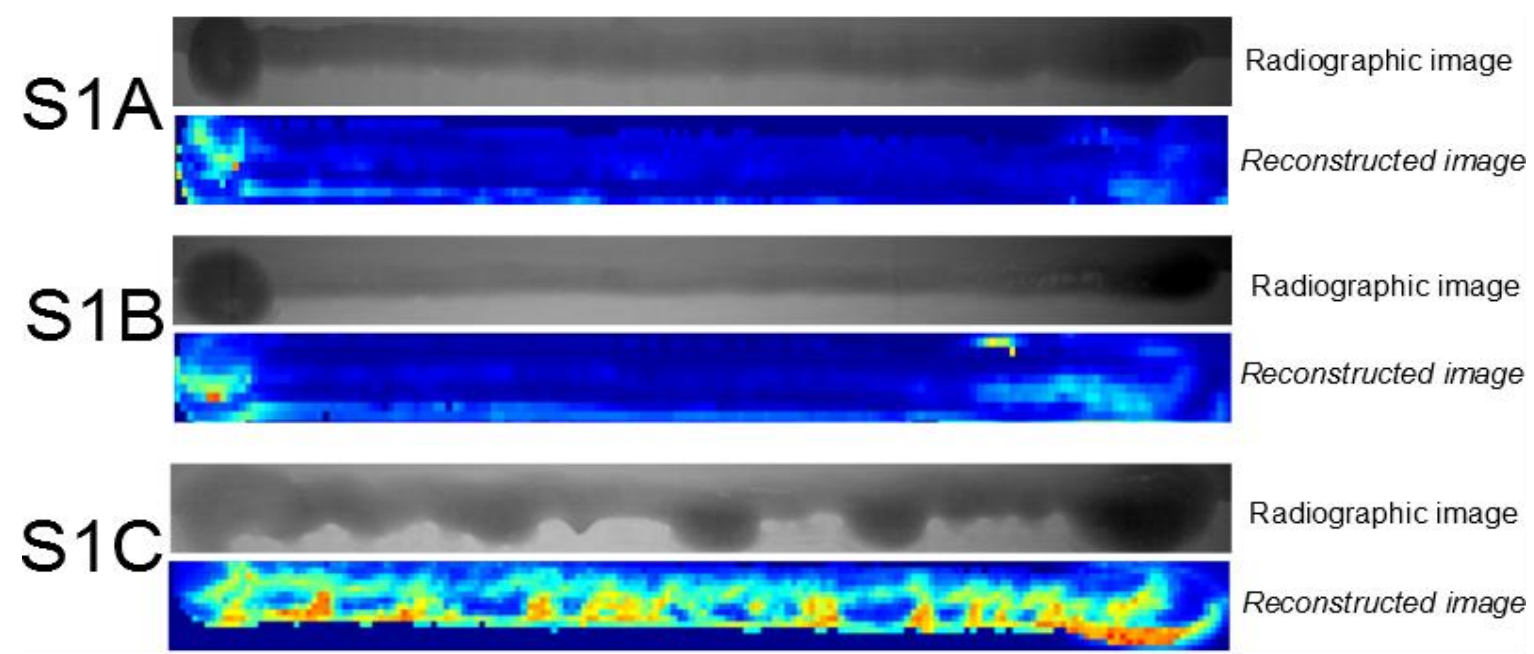

Fig. 11. Results of image processing algorithm and radiography inspections

\subsection{Experiment series 2}

Direct joining of aluminium to steel is challenging because of the huge differences in their thermo-physical characteristics and the formation of brittle inter metallic layer [6]. The presence of a third metal such as Zinc in the form of thin coating of thickness between $10-20 \mu \mathrm{m}$ [7] can enhance the wetting of the molten aluminium onto the steel surface. This thin coating can also control the formation of inter metallic layer [8]. Pre-weld temperature is an important factor which determines the wetting characteristics of the Zinc coating on the steel. The main objective of experiment series 2 is to examine the possibilities of thermal imaging in differentiating the pre weld surface temperature with respect to varying weld parameters.

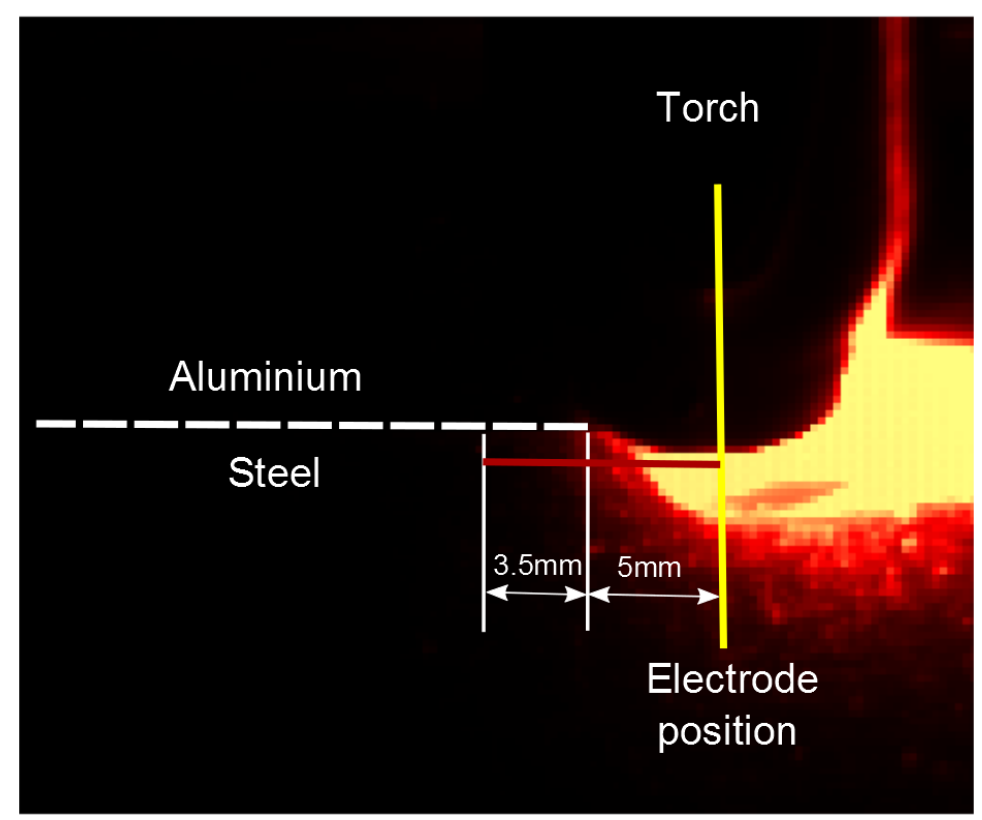

Fig. 12. Thermal image obtained during experiment series 2

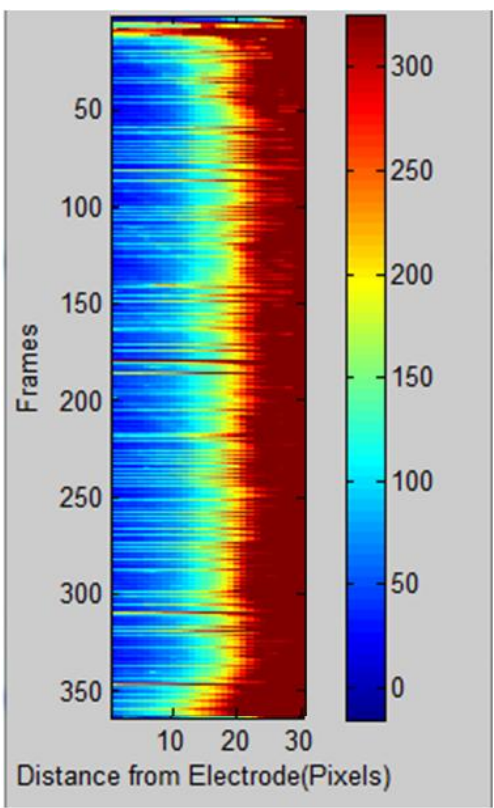

Fig.13. Regenerated pre weld temperature of a line

The infrared camera used for this inspection is a medium wave camera with a temperature range of $135-300^{\circ} \mathrm{C}$. The radiation at the wire tip and the nearby region is too high such that the acquired data at these locations are saturated. Figure 12 shows the raw thermal image obtained during the experiment. In that the yellow line corresponds to the position of the electrode tip. A horizontal line (shown in red colour in figure 12) of $8.5 \mathrm{~mm}$ parallel to the weld bead 
from the electrode tip is considered in the pre weld region. The temperature of that line is stacked vertically with respect to time and is given in figure 13. This corresponds to the temperature information of every point on the material for a distance of $8.5 \mathrm{~mm}$ away from the electrode tip. The colour scale in figure 13 corresponds to the temperature values. From figure 13 it is understood that the temperature values acquired by the camera in the nearby region of electrode tip (right end in figure 13) is saturated. So for plotting the pre weld temperature, two vertical columns of 5 pixels were selected at $5 \mathrm{~mm}$ away and $8.5 \mathrm{~mm}$ away from the electrode tip and the obtained distribution is show in figure 14 for the weld parameters given in table 3 . From the figure 14 it is evident that the pre weld temperature is different for different weld parameters and it can be effectively imaged using the explained experiment strategy.

The experiments which have been described here are relied on the relative temperature measurements as the measurement of absolute temperature is not possible without the proper emissivity values.

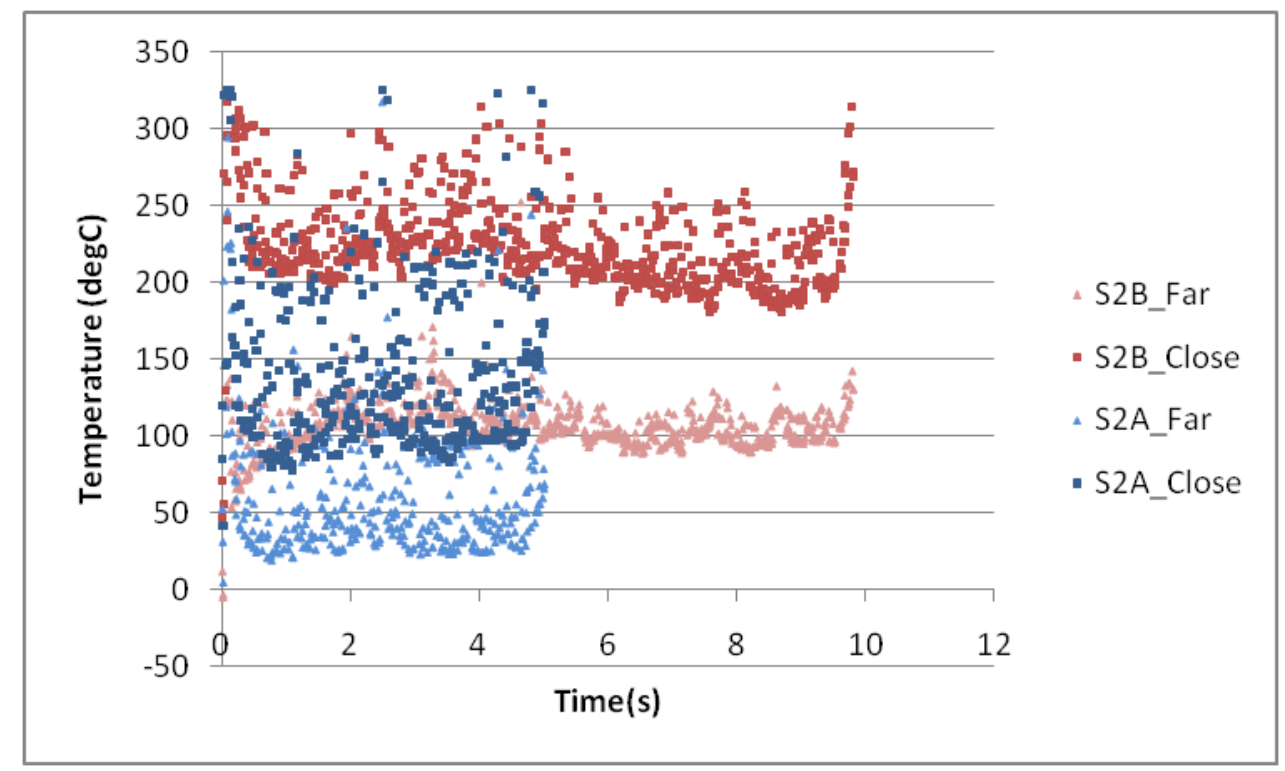

Fig. 14. Pre weld temperature of two vertical set of pixels $5 \mathrm{~mm}$ (close) and $8.5 \mathrm{~mm}$ (far) away from the electrode tip

\section{Summary and Conclusion}

Online (passive) thermographic inspection of overlap joints of aluminium and zinc coated steel sheets made by CMT weld brazing process have been carried out. Different experimental trails were conducted for demonstrating the feasibility of thermographic inspection to detect the porosities, improper weld bead and to differentiate the pre weld temperature.

The cluster of porosities, geometric perturbations of the weld bead can be clearly imaged using the discussed method. The radiographic data is closely matching with the thermographic results. The difference in the pre weld temperature and its evolution with respect to distance can also be imaged using the above said methods.

\section{Acknowledgements:}

Authors express their sincere thanks to Mr. E Anbu Rasu, Technical Officer, ARCI for his valuable assistance during the experiments and Dr. Sreedhar Unnikrishnakurup, Postdoctoral Fellow, CNDE, IITM for his inputs on the image processing of thermal images.

\section{REFERENCES}

[1] J. Feng, H. Zhang, and P. He, "The CMT short-circuiting metal transfer process and its use in thin aluminium sheets welding," Mater. Des., vol. 30, no. 5, pp. 1850-1852, 2009.

[2] N. H. Chin, B A Madsen and J. S. Goodlinc, "Infrared thermography for sensing the arc welding process," 1983. 
[3] B. Venkatraman, B. Venkatraman, M. Menaka, M. Menaka, M. Vasudevan, M. Vasudevan, B. Raj, and B. Raj, "Thermography for Online Detection of Incomplete Penetration and Penetration Depth Estimation," Asia Pacific Conf. NDT, no. figure 1, pp. 8-12, 2006.

[4] P. Bertrand, I. Smurov, and D. Grevey, "Application of near infrared pyrometry for continuous Nd: YAG laser welding of stainless steel,” Appl. Surf. Sci., vol. 168, no. 1-4, pp. 182-185, 2000.

[5] U. Sreedhar, C. V. Krishnamurthy, K. Balasubramaniam, V. D. Raghupathy, and S. Ravisankar, "Automatic defect identification using thermal image analysis for online weld quality monitoring," J. Mater. Process. Technol., vol. 212, no. 7, pp. 1557-1566, 2012.

[6] H. Dong, W. Hu, Y. Duan, X. Wang, and C. Dong, "Dissimilar metal joining of aluminum alloy to galvanized steel with Al-Si, Al-Cu, Al-Si-Cu and Zn-Al filler wires," J. Mater. Process. Technol., vol. 212, no. 2, pp. 458-464, 2012.

[7] K. Furukawa, "New CMT arc welding process - welding of steel to aluminium dissimilar metals and welding of super-thin aluminium sheets," Weld. Int., vol. 20, no. 6, pp. 440-445, 2006.

[8] H. T. Zhang, J. C. Feng, P. He, B. B. Zhang, J. M. Chen, and L. Wang, "The arc characteristics and metal transfer behaviour of cold metal transfer and its use in joining aluminium to zinc-coated steel," Mater. Sci. Eng. A, vol. 499, no. 1-2, pp. 111-113, 2009. 